\title{
A marca símbolo da campanha de prevenção às drogas
}

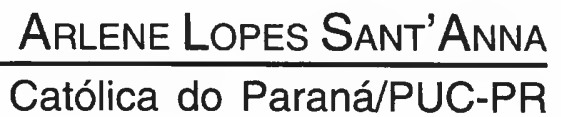

Pontifícia Universidade Católica do Paraná/PUC-PR 


\section{Resumo}

Este artigo se propõe a analisar a marca-símbolo, instituída pela APCD (Associação Parceria Contra Drogas), na campanha de prevenção às drogas veiculadas pela televisão. Esta análise leva em conta que a marca-símbolo é o texto do discurso sintético, o que identifica o objetivo dos anúncios que se apresentam para conter o consumo de drogas entre os jovens no Brasil. A marca-símbolo pertence aos domínios da semiótica visual, assim, este estudo se fundamenta na semiótica greimasiana. Podemos mostrar, por meio das relações semi-simbólicas, que a dimensão plástica se articula, por um lado com a dimensão figurativa e, por outro lado, com o enunciado linguiístico que o slogan comporta, o que instaura uma nova visão, uma nova leitura.

\section{Palavras-chave}

marca-símbolo, propaganda televisiva de prevenção às drogas, semiótica plástica, sincretismo

\section{Abstract}

This article propose to analize the simbol-mark, built by Partnership association against drugs, used in drug preventive propaganda campaign broadcasted by television. This analize consider that the simbol-mark is a speech text, which identify the aim of the announcements that is stopping the drugs consumption among brasilian young. The simbol-mark belongs to the visual semiotic, so, the methodology used in this work is the Greimas'semiotic. We can show, by relations semi-simbolics, that the present plastic frame may articulate itself with the figuratif dimension and the statement linguistic which the slong presents and then, a new vision or a new reading can be afforded.

\section{Key words}

simbol-mark, television prevent drugs propaganda, plastic semiotic, sincretism 
$\mathrm{N}$ ão é novidade afirmar que o consumo de drogas, na atualidade, é grande, pois os meios de comunicação têm divulgado esse ou aquele fato relacionado às drogas: seja no âmbito familiar; seja no criminal; seja em entrevistas, debates; e até no âmbito da ficção em telenovelas e filmes. Poder-se-ia afirmar que o assunto está banalizado tendo em vista a exploração do tema pela mídia, porém é assunto de preocupação não só do Brasil como de outros países também, uma vez que é incontrolável a escala mundial de consumo de drogas ${ }^{1}$

Em vista do panorama pessimista relativo às drogas, que já se apresenta há algum tempo, a Associação Parceria Contra Drogas $(\mathrm{APCD})^{2}$ iniciou a campanha de propaganda de prevenção às drogas como uma estratégia de combate ao consumo. Os anúncios passaram a ser veiculados pela televisão em face do prestígio deste meio o qual detém um grande potencial em atingir a maior parcela da

1. Houve a criação de uma secretaria específica para tratar de assuntos relativos às drogas SENAD (Secretaria Nacional Anti-drogas) assim como o CEBRID (Centro Brasileiro de Informações sobre Drogas) que é um centro de estudos que, inclusive, oferecem dados consistentes sobre a ascendência de consumo de drogas no Brasil.

2. No Brasil, em 1996, surge a ONG Associação Parceria contra Drogas que é a entidade responsável pelos anúncios televisivos de prevenção às drogas. Essa ONG surgiu a partir de uma proposta da embaixada norte-americana para um grupo de empresários brasileiros a fim de que este grupo realizasse uma campanha associada à Partnership for Drug-Free América. Essa campanha de combate às drogas foi iniciada nos Estados Unidos e já agregou outros países tais como: Argentina, Chile, Venezuela, Porto Rico e, atualmente, Brasil. A Associação Parceria Contra Drogas (APCD) define seus objetivos como sendo: "desvendar as drogas, difundindo seus malefícios e informando sobre os melhores métodos de prevenção contra seu uso". No Brasil, essa campanha teve o apoio do CNP (Conselho Nacional de Propaganda), apoio financeiro de empresários e emissoras de televisão as quais veiculam gratuitamente as peças de propaganda. 
sociedade. A transmissão dos anúncios da campanha iniciou, em nível nacional, a partir de outubro de $1996^{3}$ e o primeiro anúncio, $S e$ guro de Vida, pela agência Zogbi Comunicações, trouxe a público, a marca-símbolo da APCD.

A ONG, Associação Parceria Contra Drogas (APCD), instituiu a marca- símbolo como identificação de uma das ações mais abrangentes de prevenção às drogas já realizadas no Brasil. Com o primeiro anúncio da primeira campanha de prevenção às drogas, em 1996, veiculada pela televisão, surge a marca-símbolo como vínculo entre o anúncio e o referente proposto. A partir de então, a marcasímbolo é constituinte de cada novo anúncio de prevenção às drogas veiculado pela televisão.

O estudo da marca-símbolo é uma pequena parte do corpus de anúncios televisivos da campanha de prevenção às drogas já analisados, ${ }^{4}$ fundamentado na semiótica greimasiana. Entretanto, neste artigo, este estudo é retomado numa abordagem diferenciada em face de alguns acréscimos e adaptação referente ao objeto. Em acréscimos, esclarece a origem e propósito da marca-símbolo. Em adaptação, esta análise não leva a em conta a sonoridade ou a falta da mesma quando a marca-símbolo se apresenta vinculada a alguns anúncios e sim, leva em conta, especificamente e tão somente, a análise da marca símbolo, enquanto texto, em seu plano de expressão relacionado ao seu plano de conteúdo.

Cada anúncio da campanha se apresenta diversificado na construção textual, no que concerne às figuras instaladas, as substâncias ou sonoridade utilizadas no plano de expressão, assim como, um ou outro anúncio apresenta alguma variação discursiva, porém

A criação das peças depende da aprovação da comissão técnica dos especialistas engajados (médicos e psicólogos) e depois de produzidas são veiculadas na televisão. Sabe-se que desde 1996, muitas peças já foram produzidas de acordo com o que a ONG, Associação Parceria Contra Drogas, espera, ou seja, alertar a respeito dos malefícios que as drogas causam.

3. Esta informação foi constatada em pesquisa no Arquivo de Propaganda de São Paulo, empresa de iniciativa privada, responsável pelo acervo de quaisquer anúncios impressos ou televisivos do Brasil.

4. A análise da marca-símbolo é uma parte constante na dissertação de análise de 20 anúncios de prevenção às drogas. Sant'Anna, Arlene. Análise do Discurso da Propaganda de Prevenção às Drogas. Universidade de São Paulo: capítulo II, 2003. 
mantendo sempre o discurso comum de prevenção às drogas. Ao final de cada anúncio de campanha de prevenção às drogas, a marca-símbolo é veiculada das seguintes formas: em alguns anúncios se apresenta visualmente; em outros, ouve-se apenas uma batida concomitante à apresentação visual; em outros, ouve-se a voz in off confirmando o slogan concomitante ao visual e, em outros, ouvemse a batida e a voz in off, a qual confirma o slogan, juntamente com o visual da marca-símbolo. Como já justificado, a análise proposta se restringe, exclusivamente, ao visual como objeto de significação e não caberia, neste momento, estender o significado em relação à sonoridade, haja vista que seria necessário fazer relação a algum anúncio e respectiva sonorização instalada.

A marca-símbolo se apresenta sempre com o mesmo visual, ou seja, é o mesmo texto, é o mesmo plano de expressão que tem o encargo de suportar o plano de conteúdo, de expressar o discurso comum e básico de prevenção às drogas. Daí a importância da marca-símbolo da campanha devido aos seus atributos funcionais. As funções da marca-símbolo são: identificação da campanha de prevenção às drogas; finalidade de se fixar na memória do espectador; sintetiza o discurso da campanha e, por sintetizar o discurso, manifestado em texto, a marca-símbolo, deve e é redundante, mas com o propósito de ratificação da mensagem.

Dessa feita, é procedente descrevermos como se apresenta a marca-símbolo. Esta é composta da logomarca, que é a representação visual e abstrata, e do slogan, que é a representação verbal. É um texto sincrético, pois se apresenta com diferentes linguagens (gráfica, cromática, plástica) administradas, unidas e hierarquizadas na forma de único texto, como também é um texto que pertence aos domínios da semiótica visual. É pertinente justificarmos as assertivas de que a marca-símbolo é texto, é texto sincrético e é texto que pertence aos domínios da semiótica visual.

O que autoriza a legitimidade das afirmações supracitadas respectivamente são os fundamentos da semiótica francesa. Referente a 'texto', segundo Greimas (1979, pp. 460-61), texto ou textualização são entendidos como a junção do plano de conteúdo com o plano de expressão, em suas palavras: 
Considerado como enunciado, texto opõe-se a discurso, conforme a substância de expressão - gráfica ou fônicautilizada para a manifestação do processo lingüístico... ... textualização é o conjunto de procedimentos -chamados a se organizarem numa sintaxe textual- que visam à constituição de um contínuo discursivo...o texto, uma vez manifestado, assumirá a forma de uma representação semântica do discurso,

o que se depreende é que o texto é o todo de um objeto de significação passível de ser lido. Referente à marca-símbolo ser um 'texto sincrético', Floch (1986, p. 233) define que

As semióticas sincréticas (no sentido de semióticas objetos, quer dizer, das magnitudes manifestadas que dão a conhecer) se caracterizam pela aplicação de várias linguagens de manifestação. Um 'spot' publicitário, uma historieta, um telejornal, uma manifestação cultural ou política são, entre outros, exemplos de discursos sincréticos." (...) Semióticas sincréticas constituem seu plano de expressão - e mais precisamente a substância de seu plano de expressão - com os elementos dependentes de várias semióticas heterogêneas. Afirma-se assim a necessidade - e a possibilidade - de abordar estes objetos como 'todo' de significação (...).

O texto pertence à 'semiótica visual' (também chamada de semiótica plana ou bi-dimensional) por seus caracteres artificiais e construídos, ou seja, opõe-se às línguas naturais. Segundo Greimas e Floch $^{5}$ (1985, p. 20)

Admite-se definir a semiótica visual pelo seu caráter construído, artificial, opondo-se desse modo a língua

5. A afirmação descarta o caminho da semiologia, que teve como maior figura Roland Barthes: a identificação, descrição e classificação dos signos como base do reconhecimento de figuras e imagens do mundo. 
'natural' e ao mundo 'natural'... 'natural' visto que se apresenta transcodificada no interior de nossos discursos e artificial, já que constitui sob a forma de imagens, um componente essencial da linguagem poética construída.

A construção da marca-símbolo é composta de diferentes substâncias no plano de expressão -cromática, plástica, gráfica, já mencionadas anteriormente.

Greimas e Floch (1985, p. 18) ensinam que, no plano de expressão, podem ser reconhecidos formantes figurativos e formantes plásticos. Greimas (s/d) faz duas reflexões importantes sobre as 'figuras' e a 'figuratividade': a primeira é que o reconhecimento daquela

é de natureza social, estando, portanto, sujeito ao relativismo cultural (...). Cada cultura dotada de uma 'visão de mundo' que lhe é própria, impõe por isso mesmo condições variáveis ao reconhecimento dos objetos $e$, conseqüentemente, à identificação das figuras visuais como algo que 'representa' os objetos do mundo, contentando-se freqüentemente com esquematismos vagos, mas exigindo, por vezes, reprodução minuciosa dos detalhes 'verídicos'; (p. 25)

a segunda, é que o reconhecimento desta,

entendida como um certo modo de leitura -e um modo de produção-das 'superfícies construídas' não se acha necessariamente ligada a uma normalidade qualquer $e$ que ela pode dar lugar a excessos e insuficiências: o desejo de fazer-parecido - de fazer-crer - manifestado por este ou aquele pintor, por esta ou aquela escola, por esta ou aquela época leva, mediante a associação e sobrecarga de traços visuais, à iconização. Para o autor, os formantes plásticos servem de "pretexto para investimentos de significações outras, o que nos autoriza a falar de linguagem plástica e a circunscrever suas especificidade. (Greimas (s/d), p. 36). 
Um objeto planar construído, como a marca-símbolo, produz efeitos de sentido, é um objeto significante e como tal, faz parte de um sistema semiótico e, por assim dizer, passível de ser analisado, de ser lido. Greimas(s/d) explica que a exploração do significante plástico começa pela constituição de um campo relativo às condições topológicas tanto da produção como da leitura do objeto planar, um quadro formato que o autor define:

Ato deliberado do produtor que, colocando-se ele próprio no espaço da enunciação 'fora-do-quadro' instaura, por meio de uma espécie de debreagem, um espaço enunciado do qual será o único comandante, capaz de criar um 'universo utópico' separado desse ato: garantindo, desse modo, ao objeto circunscrito o estatuto de 'um todo de significação' esse fechamento é também o ponto de partida das operações de deciframento da superficie enquadrada. (p. 32).

Os formantes plásticos do plano de expressão estão relacionados às estratégias específicas para a percepção do sensível. Não se quer dizer que um texto, no seu plano de conteúdo, onde o texto diz o que diz, lugar do 'inteligível' (e do 'passional') não mobiliza também nossa sensibilidade, afirma-se tão somente que o plano da expressão, pensado não só para "carregar" os conceitos como também para ser o lugar do 'sensível', dos efeitos de contrastes, movimentos, profundidade entre tantos outros, trabalha os sentidos de uma maneira mais direta, menos mediada pela razão. Considerando, então, que os formantes plásticos, que se relacionam às estratégias para a percepção dos sentidos, dividem-se em três categorias: topológica, cromática e eidética, as quais, por sua vez, estão ligadas à posição, às formas e às cores pertinentes ao objeto do estudo.

Vale lembrar que a abordagem deste estudo, até agora, tem se referido ao plano de expressão, porém convém destacar que o plano de expressão de um objeto significativo está estreitamente relacionado ao seu plano de conteúdo, pois na análise do 
texto sincrético, analisam-se as linguagens utilizadas na construção do objeto em busca do todo significativo, o que implica, obviamente, na análise das categorias do plano de conteúdo a fim de relacionálas com as categorias do plano de expressão, ou seja, a marcasímbolo apresenta o sistema semi-simbólico ${ }^{6}$.

As possibilidades de análise do plano da expressão e sua relação com o plano de conteúdo, referem-se principalmente a textos visuais. Se considerarmos que um texto sincrético pode perfeitamente unir uma reprodução de uma pintura famosa, um trecho de uma poesia manifestada em tipos gráficos não padronizados, junto a fundos coloridos, entre outros recursos, percebe-se um grau maior de complexidade para quem pretenda decifrá-lo.

A marca-símbolo

DROGAS. NEM MORTO.

\section{Significante da marca-símbolo}

Inicia-se a análise pelo plano de expressão, pelo significante da marca-símbolo, pois este assume o encargo de suportar o significado, ou seja, expressa o conteúdo do texto. $\mathrm{O}$ que implica no exame das

6. O sistema semi-simbólicos se define pela relação entre as categorias do plano de expressão e o plano de conteúdo. 
categorias do sistema semi-simbólico da marca-símbolo. Nas palavras de Barros (1997, p. 82),

Os sistemas semi-simbólicos podem ser denominados poéticos e ocorrem no texto literário, na pintura, no desenho, ... procuram obter efeitos de sentido de recriação da realidade, de adoção de um ponto de vista novo na visão e no entendimento do mundo.

O plano de expressão da marca-símbolo contempla as seguintes categorias semi-simbólicas:

Categoria constitucional cromática

Tonalidade $\rightarrow$ quente $\mathrm{x}$ frio $\rightarrow$ associando o vermelho ao sangue e o branco ao lívido da morte ${ }^{7}$

\section{Categorias relacionais eidéticas}

Forma $\rightarrow$ angular $\mathrm{x}$ arredondado $\rightarrow$ referentes aos ângulos do losango e à mão arredondada. $\rightarrow$ reto $\mathrm{x}$ curvo $\rightarrow$ referentes aos lados do losango e à curva da linha da vida. $\mathrm{O}$ losango com sangue para, por meio da linha da vida, irriga a mão esvaída de sangue.

Categorias relacionais topológicas

Orientação $\rightarrow$ frente $\mathrm{x}$ atrás $\rightarrow$ o losango atrás e a mão na frente. Dimensão $\rightarrow$ grande $\mathrm{x}$ pequeno $\rightarrow$ o losango maior que a mão remetem a um espaço bem maior para abrigar a mão que, como já mencionado, oferece a vida.

7. O pintor $V$. Kandinsky exprimiu-se sobre a cor branca melhor do que ninguém $O$ branco, que muitas vezes se considera como uma não-cor...é como o símbolo de um mundo onde todas as cores, em sua qualidade de propriedade materiais se tenham desvanecido... O branco produz sobre a nossa alma o mesmo efeito do silêncio...um nada anterior a todo nascimento, anterior a todo começo. $A$ terra, branca e fria, talvez tenha ressoado assim, nos tempos da era glaciária. Vassili Kandinsky, 1989. 


\section{Esquema do sistema semi-simbólico da Marca-Símbolo}

\section{PLANO DE EXPRESSÃO}

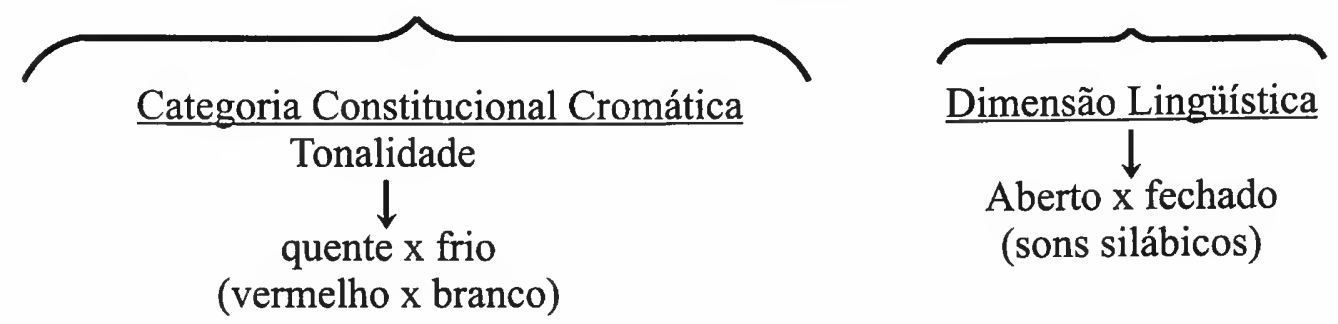

Categorias Constitucionais Eidéticas

Reto x Curvo Angular x Arredondado

(lados x linha) (ângulos x mão)

Categorias Relacionais Topológicas

Orientação Dimensão

Frente $x$ Atrás Grande $x$ Pequeno

(mão $x$ losango) (losango $x$ mão)

Categoria de Conteúdo

Extenso $\mathrm{x}$ Intenso

(vida) (morte)

\section{PLANO DE CONTEÚDO}

Podem se relacionar as categorias do plano de conteúdo com as do plano de expressão como se segue.

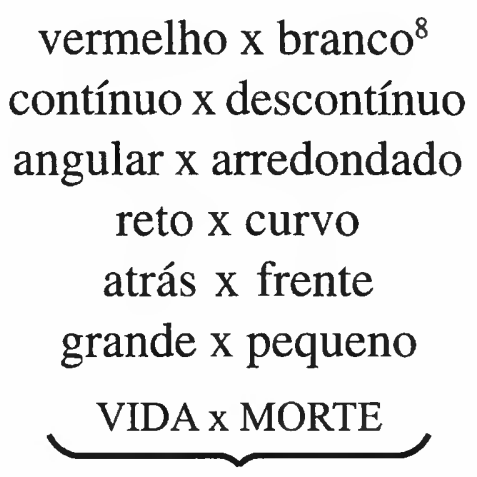

8. A cor vermelha, considerada cor quente, a cor branca, considerada, cor fria. 


\section{Significado da marca-símbolo}

O visual da logomarca conta com dois triângulos isósceles, formando um losango em vermelho e, sobreposto ao losango, a mão espalmada em branco e a linha da vida, em vermelho. A área do losango e a mão espalmada gestual indicativa de Pare constituem a expressão de uma colocação em correspondência das significações de uma placa de trânsito e a marca-símbolo, em outras palavras, a marca-símbolo, em sua totalidade, remete à representação das placas de trânsito (proibido estacionar, preferencial etc.), o que já indica uma intertextualidade por alusão numa relação contratual.

A cor quente vermelha do losango remete a sangue, à vida e o branco 9 da mão espalmada, remete à morte. Essa assertiva leva em conta que o vermelho do losango é o sangue que irriga a mão branca, sem vida, de um branco lívido por meio da linha da vida. Vale ressaltar que a linha palmar é denominada e reconhecida pelo senso comum por linha da vida. Assim, não só a mão, mas a linha da vida são reconhecidas como figuras do mundo natural que a cultura reconhece.

O slogan, Drogas. Nem morto., utịliza letras de traços grossos e, sabe-se que, o emprego de letras com traços grossos é convencional na comunicação ocidental (negrito) quando no tratamento de assuntos sérios e de importância. ${ }^{10}$ Ainda, apresenta sílabas abertas em contraste com sílabas fechadas: Dro/gas. Nem/ mor/to. Considerando o enunciado do slogan, Drogas. Nem morto., o emprego de elipse, no enunciado, corresponde a Drogas, não use de forma alguma, ou a em nenhuma circunstância.

O texto, resultante da junção do plano de expressão com o plano de conteúdo, construído sob a forma de um percurso gerativo, oferece a totalidade significativa na produção de efeitos de sentido. Como se pode constatar, o texto examinado, na perspectiva semiótica,

9. Já explicitado, segundo o pintor V. Kandinsky, 1989, p. 4.

10. É comum notar o emprego de negrito em manchetes de jornais, inclusive, para chamar mais a atenção. (Rabaça; Barbosa,1995, p. 415).

$\overline{\text { Significação } 20 \bullet 216}$ 
produz efeito de sentido de verdade, de realidade, um alerta da importância da vida, mesmo porque, há de se considerar que a marca-símbolo vinculada aos anúncios, ratifica a prevenção às drogas.

A marca-símbolo, sob o ponto de vista semântico, mostra a vida que é representada pelo sangue que irriga vida à mão e a morte é representada pelo branco lívido da mão. O que se pressupõe a vida, como objeto de valor, a morte, como possível sanção, e as drogas como anti-sujeito. O sujeito da enunciação fez as escolhas da figura (mão no losango), das cores, da disposição visual, do slogan, o que se pressupõe um narrador implícito que se dirige a um narratário pressuposto. Considerando que todo texto possui componente narrativo, a marca-símbolo não foge à regra, pois, por exemplo, as pressuposições de sanção e as drogas como anti-sujeito, já mencionadas, indicam marcas de transformações apresentadas no texto.

É no enunciado que se buscam as projeções da enunciação. Como parte das estratégias discursivas do sujeito da enunciação, este desembreou os sujeitos discursivos (narrador e narratário), pois se pressupõe, no enunciado, um $E u$ para declarar e um Você a quem é dirigida a declaração; (Eu declaro que) Drogas. (não use você) Nem morto. Neste aspecto, apresenta as desembreagens enunciativas pessoais, temporais e espaciais: o narrador pressuposto que declara eu; o tempo presente da declaração agora, considerando o imperativo use implícito, o que caracteriza procedimento de persuasão e aqui, da apresentação do anúncio. $\mathrm{O}$ enunciador da marca-símbolo ${ }^{11}$, ao instalar as projeções, em pessoa, espaço e tempo, cria efeitos de atualidade e de verdade, baseado em fatos ocorridos em um momento de referência pretérita e alhures. Assim se apresenta o simulacro discursivo do enunciador e enunciatário implícitos.

Haja vista que a marca-símbolo está em todos os anúncios da campanha, ao se assistir a um anúncio, se estabelece uma relação entre o anúncio e a marca-símbolo, porque, ao dispor da linguagem televisiva, o sujeito da enunciação utiliza várias estratégias para

11. A referência ao enunciador da marca-símbolo não quer dizer que se distingue do enunciador do anúncio, porém para efeito de clareza, parece mais adequado, visto que, no momento, o que interessa é a abordagem da marca-símbolo.

Significação $20 \cdot 217$ 
estabelecer o contrato entre o enunciador e o enunciatário, principalmente em se tratando de marca-símbolo, pois o verdadeiro valor da marca-símbolo reside na idéia proposta pela campanha de prevenção às drogas e, em função disso, o enunciador deve comunicar para advertir e convencer, deve levar o enunciatário a um devernão-fazer, a um querer-não-fazer e a um dever-saber, em outras palavras, dever não fazer uso de drogas, querer não usar drogas e dever saber sobre os malefícios que as drogas causam.

O que é importante no processo comunicativo, segundo a semiótica, é o fazer-crer. A marca-símbolo sintetiza o discurso da campanha alertando sobre o perigo do uso das drogas, prevenindo sobre as consequiências do consumo para qualquer enunciatário, para isso, inclusive, expressa uma correspondência à significação de placa de trânsito, o que se constata é que há um destaque maior na logomarca em detrimento ao slogan.

A marca-símbolo indica que a comunicação é dirigida a qualquer enunciatário, visto que, ao remeter a marca-símbolo à representação de placas de trânsito, figura reconhecida pela cultura, favorece a ampliação da comunicação. Não se ignora que a fixação e a identificação da marca-símbolo da campanha é de fundamental importância e, para isso, o autor de papel deve pensar na síntese mais adequada e, ao mesmo tempo, mais abrangente do discurso apresentado por qualquer anúncio da campanha.

Assim, desde 1996, a marca-símbolo tem se consolidado no reconhecimento, pelo senso comum, como identificadora da campanha de prevenção às drogas, pois que, a cada novo anúncio a ser veiculado, a cada variação discursiva que possa se apresentar, a marca-símbolo constitui e institui a essência da campanha. 


\section{Bibliografia}

APCD - Associação Parceria Contra Drogas. Marca-símbolo. www.pareceriacontradrogas.com.br

BARROS, Diana Luz Peśsoa de. 2001. Teoria do discurso: fundamentos semióticos. São Paulo: Humanitas/FFLCH/USP.

1986. Texto e imagem. Linguagens Revista Brasileira da Região Sul - Associação Brasileira de Semiótica - número 1, out.

1988. Revista de linguagens. Porto Alegre, RS. (xerox)

1997. Teoria semiótica do texto. São Paulo: Ática.

FIORIN, José Luiz. 1999. As astúcias da enunciação: categorias de pessoa, espaço e tempo. São Paulo: Ática.

FLOCH, Jean-Marie. 1985. Petites Mythologies de L'oeil e de L'espirit - Pour une Sémiotique Plastique. Paris-Amsterdam: Hadès-Benjamins.

GREIMAS, Aljirdas Julien. s/d. Semiótica figurativa e semiótica plástica. (xerox).

GREIMAS, A. J; COURTÉS, J. 1986. Semiótica - Diccionario razonado de la teoría del languaje, tradução espanhola de Enrique Ballón Aguirre. Biblioteca Românica Hispânica, Gredos.

GREIMAS, A. J; COURTÉS, J. 1979. Dicionário de semiótica. São Paulo: Cultrix.

KANDINSKY, V. 1989. Du spirituel dans L'art, Paris, 1954. In: CHEVALIER, Jean et alii. Dicionário de símbolos. RJ: José Olímpio.

LEITE, Eduardo Afonso F. 2002. Análise Discursiva de uma Campanha Publicitária de Prevenção ao Uso de Drogas. Dissertação de Mestradp. São Paulo: PUC.

RABAÇA, Carlos Alberto; BARBOSA, Gustavo. 1995. Dicionário de Comunicação. São Paulo: Ática.

SABORIT, José. 1992. La imagen publicitaria en television. Madrid: Cátedra. 